\title{
Optimal location of subtrochanteric osteotomy in total hip arthroplasty for crowe type IV developmental dysplasia of hip
}

Zhe-Yu Huang, Hua Liu, Ming Li, Jing Ling, Jun-Hui Zhang and Zhi-Min Zeng*

\begin{abstract}
Background: When reconstructing a hip with developmental dysplasia and high dislocation, sub-trochanteric shortening osteotomy is typically needed for placing the acetabular component in the appropriate anatomical position. However, the procedure can result in complications such as non-union of the osteotomy. We evaluated the contact area and the coincidence rate between the proximal and distal fragments at different femoral osteotomy levels and lengths. We then determined the optimal location of subtrochanteric femoral shortening transverse osteotomy in patients with unilateral Crowe type IV developmental dysplasia of the hip (DDH). The consistency between the proximal and distal segments was assessed as a possible predictive indicator of the union at the osteotomy site.
\end{abstract}

Methods: We retrospectively reviewed 57 patients with unilateral Crowe type IV DDH who underwent X-ray imaging of both hip joints. We labelled the inner and outer diameters of the circular ring as $\mathrm{N}(\mathrm{mm})$ and $\mathrm{M}(\mathrm{mm})$, respectively. We defined the overlapped area between the proximal and distal ring as contact area $S\left(\mathrm{~mm}^{2}\right)$, and the ratio of contact area to distal ring area as coincidence rate $\mathrm{R}$.

Results: $\mathrm{N}$ varied from 9.8-15.2 mm and $\mathrm{M}$ varied from 20.7-24 mm, both demonstrated a decreasing trend in the proximal to distal direction. At osteotomy lengths ranging from $0.5-2 \mathrm{~cm}$, there were no differences in $\mathrm{S}$ between the different levels of osteotomy in each group. At osteotomy lengths $\leq 2.5 \mathrm{~cm}$, a significant higher coincidence rate was noted from $2 \mathrm{~cm}$ below the lesser trochanter to other positions below the level. At osteotomy lengths from 3 to $5.5 \mathrm{~cm}$, a significantly higher coincidence rate was observed from the level of $1.5 \mathrm{~cm}$ below the lesser trochanter to other positions below the level.

Conclusions: Our findings suggest that femoral shortening transverse osteotomy at the optimal subtrochanteric level can predictably increase the contact area and coincidence rate, which may contribute to the union at the osteotomy site. Considering the stability of the prostheses, it appears appropriate that osteotomy location should be shifted slightly distally.

Trial registration: Retrospectively registered.

Keywords: Developmental dysplasia of the hip, Femoral shortening transverse osteotomy, Non-union, Contact area, Optimal location

\footnotetext{
*Correspondence: zhiminzeng_joint@163.com

The Department of Orthopedics Surgery, Ningbo No. 6 Hospital, 1059\#

ZhongShan East Road, Ningbo, Zhejiang 315040, People's Republic of China
}

(C) The Author(s). 2020 Open Access This article is licensed under a Creative Commons Attribution 4.0 International License, which permits use, sharing, adaptation, distribution and reproduction in any medium or format, as long as you give appropriate credit to the original author(s) and the source, provide a link to the Creative Commons licence, and indicate if changes were made. The images or other third party material in this article are included in the article's Creative Commons licence, unless indicated otherwise in a credit line to the material. If material is not included in the article's Creative Commons licence and your intended use is not permitted by statutory regulation or exceeds the permitted use, you will need to obtain permission directly from the copyright holder. To view a copy of this licence, visit http://creativecommons.org/licenses/by/4.0/ The Creative Commons Public Domain Dedication waiver (http://creativecommons.org/publicdomain/zero/1.0/) applies to the data made available in this article, unless otherwise stated in a credit line to the data. 


\section{Background}

Total hip arthroplasty (THA) is the gold standard treatment in end-stage hip disorders, such as osteoarthritis, rheumatoid arthritis, and hip dislocation that leads to significant pain and loss of function [1]. Performing THA in Crowe type IV developmental dysplasia of the hip (DDH) is technically demanding and does present many challenges to the surgeon in terms of both the femoral and acetabular sides. One of the most important steps is transferring the hip into the anatomical center of rotation for durable results and correcting the functions of the abductor muscles [2, 3]. When restoring the anatomical center of hip rotation, the leg may be lengthened by over $4 \mathrm{~cm} \mathrm{[4],} \mathrm{which} \mathrm{increases} \mathrm{the} \mathrm{risk} \mathrm{of} \mathrm{direct}$ or indirect neurologic injury [5]. Consequently, subtrochanteric femoral shortening osteotomy was introduced to facilitate pulling down of the femur, correct the rotational abnormalities, preserve the proximal femoral metaphysis, and reduce the risk of nerve injury [6].

Various subtrochanteric osteotomy techniques with other cutting shapes, transverse, oblique, doublechevron, and Z-shaped, have been previously described [7-13]. Transverse osteotomy may be recommended because of the technical simplicity in adjusting the anteversion angle and minimal damage of the periosteum at the osteotomy site $[14,15]$. However, the risk of non-union remains a major concern during the procedure [16, 17]. A limited bone contact area is a major disadvantage of transverse osteotomy, which may interfere with the bone healing process $[18,19]$. The consistency of the interfaces and canal diameters between the proximal and distal segments may contribute to union; the two osteotomy interfaces should be as smooth as possible to maintain their intactness [20].

In order to assess the consistency between the proximal and distal segments as a potential predictive indicator of the union of the osteotomy site, we evaluated the contact area and coincidence rate between the proximal and distal fragments at different levels and lengths of femoral osteotomy. We then determined the optimal location of subtrochanteric femoral shortening transverse osteotomy in patients with Crowe type IV DDH.

\section{Methods}

We searched our Medical Image Database using our hospital's picture archiving and communication system (PACS) and retrospectively reviewed the X-ray data of 102 patients with a high dislocation of the hip between 2010 and 2018. The inclusion criteria for this study were: (1) unilateral Crowe type IV DDH with a normal contralateral hip, and (2) the hip radiograph in the anteroposterior (AP) position included a fixed reference, such as a Yuan coin. The exclusion criteria included previous surgical history or fractures with deformities. Of the 102 patients, the following were excluded: 14 patients due to bilateral hip diseases, 8 patients without DDH of Crowe IV category, 18 patients without images with a fixed reference, and 5 patients who had undergone a prior ipsilateral hip surgery. Subsequently, we evaluated 57 patients with unilateral Crowe type IV DDH (Fig. 1), and these were comprised of 46 females and 11 males with an overall mean age of 53 years (range, 20-75).

The AP radiographs were imported into Adobe Photoshop CS6 software v13.0 (Adobe Systems, Inc., San Jose, CA, USA) for image processing and calculating the measurements. First, we magnified or shrunk the radiographs to fit the actual size of the coin. Second, we drew two parallel lines along the inner and outer cortex of the femoral shaft, and then drew a midline of the two parallel lines as the femoral anatomic axis, and last, we drew sixteen vertical lines perpendicular to this axis from 0 to $8 \mathrm{~cm}$ below the lesser trochanter at $0.5 \mathrm{~cm}$ intervals (Fig. 2). The reasons we regarded the $8 \mathrm{~cm}$ mark below the lesser trochanter the most distant point were the following: (1) most osteotomies located at the proximal femur, including immediately distal to the lesser trochanter [21-25], are at $1-3 \mathrm{~cm}$ below the lesser trochanter [7, 20, 26, 27]; and (2) according to Su et al. [28], the femoral isthmus begins $8 \mathrm{~cm}$ below the lesser trochanter, which influences the stability of the prosthesis and, therefore, osteotomy should not be performed at or beyond this level.

In order to measure the area of cross-section of osteotomy, each section was assumed to be in the shape of a circular ring. We labelled the inner diameter of the circular ring as $\mathrm{N}(\mathrm{mm})$, and the external diameter as $\mathrm{M}$ $(\mathrm{mm})$. We identified the overlapping area between the proximal and distal rings as the contact area, $\mathrm{S}\left(\mathrm{mm}^{2}\right)$, and the ratio of contact area to distal ring area as coincidence rate, $\mathrm{R}$ (Fig. 3). Mathematically, $S=\frac{\pi\left(M_{D}^{2}-N_{P}^{2}\right)}{4}$, which was simplified to $\left(\mathrm{M}_{\mathrm{D}}{ }^{2}-\mathrm{N}_{\mathrm{P}}{ }^{2}\right)$, and $R=\frac{M_{D}^{2}-N_{P}^{2}}{M_{D}^{2}-N_{D}^{2}}$. Overall, 17 sets of data for $M$ and $N$, ranging from 0 to $8 \mathrm{~cm}$ below the lesser trochanter at $0.5 \mathrm{~cm}$ intervals were measured. We divided the length of osteotomy from 0.5 to $7 \mathrm{~cm}$ at intervals of $0.5 \mathrm{~cm}$ and named the proximal location of osteotomy as the level of osteotomy. According to the measured data, we obtained 14 groups of data for the contact area $\mathrm{S}$ and coincidence rate $\mathrm{R}$ for different osteotomy lengths. We only measured the levels from 0 to $8 \mathrm{~cm}$ below the lesser trochanter at intervals of $0.5 \mathrm{~cm}$; therefore, different groups had a different number of levels of osteotomy, i.e., different groups had a different number of observations for $\mathrm{S}$ and $\mathrm{R}$ values. With an increase of $0.5 \mathrm{~cm}$ in the length of osteotomy, the number of observations decreased by one. Therefore, the group with an osteotomy length of $0.5 \mathrm{~cm}(0.5 \mathrm{~L}$ 


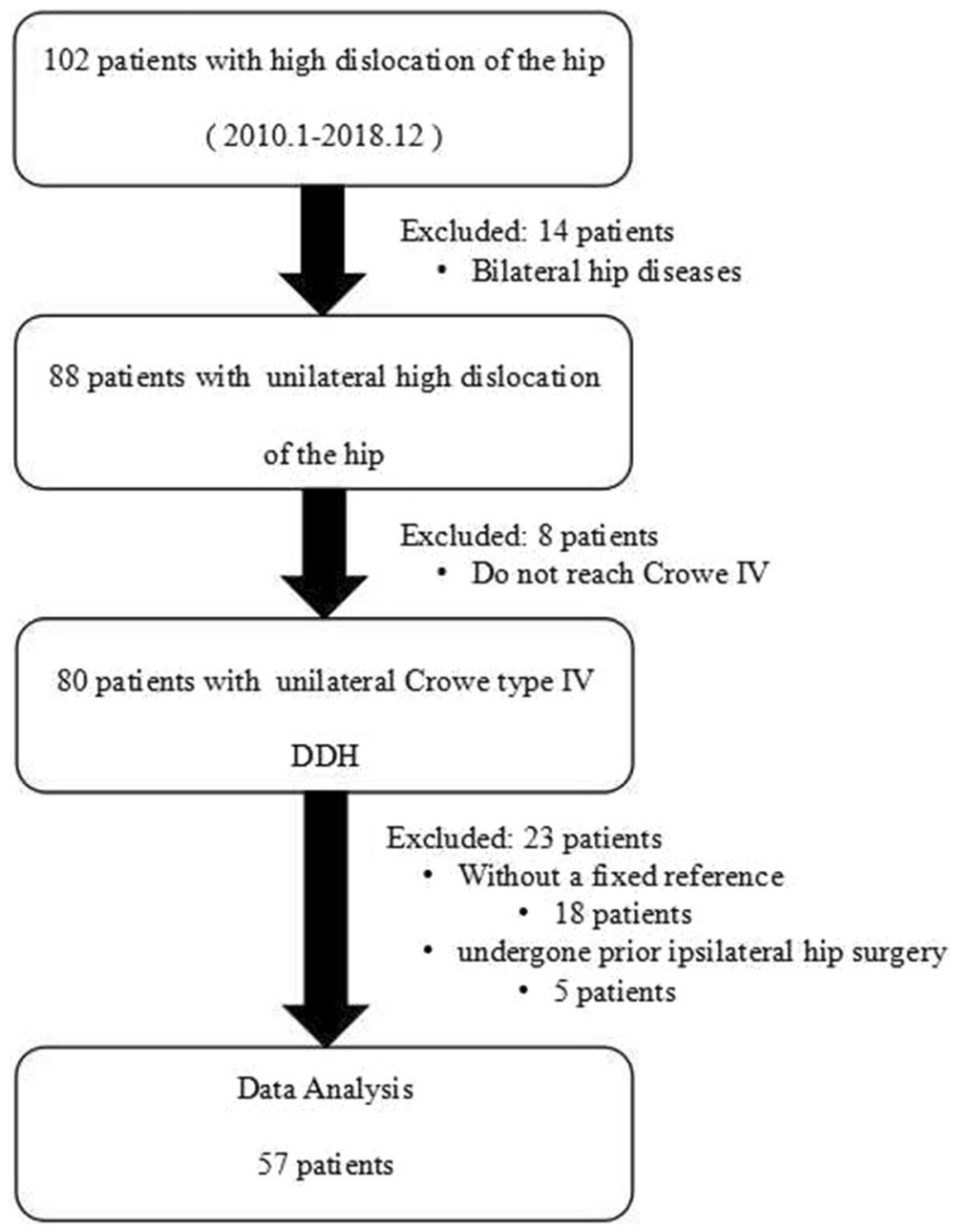

Fig. 1 Flowchart depicting the selection of hips to be evaluated

group) had 16 levels, the group with osteotomy at $1 \mathrm{~cm}$ length (1 L group) had 15 observations, and the group with osteotomy at $1.5 \mathrm{~cm}$ length $(1.5 \mathrm{~L}$ group) had 14 observations, and so on. We incorporated a simple correction to the data. If $M_{P} \geq M_{D}$, and $N_{P} \leq N_{D}$, or $M_{D} \geq$ $M_{P}$, and $N_{D} \leq N_{P}$, then $R$ was equal to 1 . If $M_{D} \leq N_{P}$, then coincidence rate $R$ was equal to 0 .

Statistical analyses were performed using SPSS software v24.0 (IBM Inc., Armonk, NY, USA). In each group, intra-group comparisons of $\mathrm{S}$ and $\mathrm{R}$ values were performed separately using one-way analysis of variance (ANOVA) and Student-Newman-Keuls test (q-test). The level of significance was set at $p<0.05$.

\section{Results}

The average $\mathrm{N}$ values were 15.2 and $9.8 \mathrm{~mm}$ at just below the lesser trochanter and $8 \mathrm{~cm}$ below the lesser trochanter, respectively. The average $M$ values were 24 and $20.7 \mathrm{~mm}$ at approximately distal to the lesser trochanter and $8 \mathrm{~cm}$ below the lesser trochanter, respectively. Both, average $\mathrm{M}$ and $\mathrm{N}$ values, demonstrated a gradually decreasing trend distally. The detailed measurements are summarized in Table 1.

In the $0.5 \mathrm{~L}$ group, the minimum $\mathrm{S}, 315.4 \mathrm{~mm}^{2}$, was at the level just below the lesser trochanter, while the maximum $S$, $339.9 \mathrm{~mm}^{2}$, was located at $1 \mathrm{~cm}$ below the lesser trochanter. There was no statistical difference in $\mathrm{S}$ between the different levels of the $0.5 \mathrm{~L}$ group $(p=1)$. In groups with osteotomy at $1-2 \mathrm{~cm}$, no statistical difference in $\mathrm{S}$ between the levels of osteotomy in the three groups was observed ( $p=0.807$ for 1 $\mathrm{L}$ group, $p=0.36$ for $1.5 \mathrm{~L}$ group, $p=0.071$ for $2 \mathrm{~L}$ group). In the $2.5 \mathrm{~L}$ group, the minimum $\mathrm{S}, 231.4 \mathrm{~mm}^{2}$, appeared at the level of just below the lesser trochanter; the $S$ value of this level was significantly lower than those in the other levels $(p=0.003)$. In the remaining nine groups, no statistical difference was noted in the levels of osteotomy, except for the level of just below the lesser trochanter, which had the smallest $\mathrm{S}$ value in each group. These data are summarized in Table 2; the results of ANOVA and q-test of each group are shown in Additional files 1, 2, 3, 4, 5, 6, 7, 8, 9, 10, 11, 12,13 and 14 . 


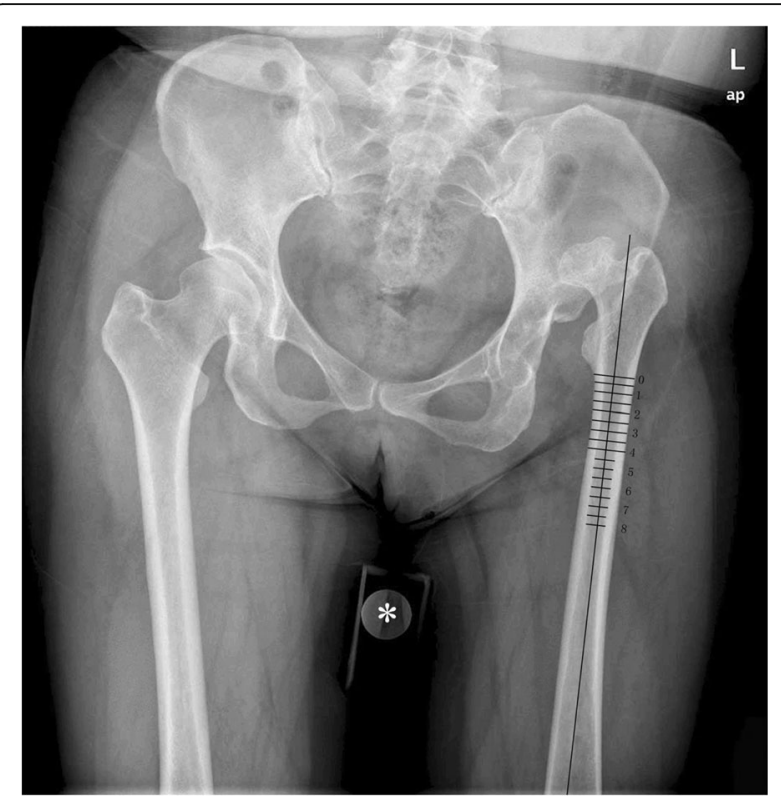

Fig. 2 The inner and external diameters of each level of osteotomy on anteroposterior view on the radiograph. ${ }^{*} \mathrm{~A}$ fixed reference, one-yuan coin
We also observed significant results in the $\mathrm{R}$ values. In the $0.5 \mathrm{~L}$ group, the minimum $\mathrm{R}, 86 \%$, was observed at the level of just below the lesser trochanter. The $\mathrm{R}$ values were 90.8, 94.2, and $95.2 \%$ for the levels of $0.5,1$, and $1.5 \mathrm{~cm}$ below the lesser trochanter, respectively. A statistically significant decrease was found in $\mathrm{R}$ in the four proximal levels above the level of $2 \mathrm{~cm}$ below the lesser trochanter in comparison to those below this level $(p<0.0001)$. Similar results were observed in $1 \mathrm{~L}, 1.5 \mathrm{~L}$, $2 \mathrm{~L}$, and $2.5 \mathrm{~L}$ groups. In the $3 \mathrm{~L}$ group, the $\mathrm{R}$ values were $61,73.5$, and $81.5 \%$ for the levels of $0,0.5$, and $1 \mathrm{~cm}$ below the lesser trochanter, respectively. From the level of $1.5 \mathrm{~cm}$ below the lesser trochanter to other levels below this level, there was a significant increase in the $\mathrm{R}$ values in comparison to the three proximal levels. With respect to the length of osteotomy ranging from 3.5 to $5.5 \mathrm{~cm}$, the results were similar to those of the $3 \mathrm{~L}$ group. In the $6 \mathrm{~L}$ group, the $\mathrm{R}$ values were $55.2,67.5,76.3,82.4$, and $86.3 \%$ for the levels of $0,0.5,1,1.5$, and $2 \mathrm{~cm}$ below the lesser trochanter, respectively. According to the qtest, there was a significant increase in the $R$ value at the distal three levels in comparison to the two proximal levels. In the $6.5 \mathrm{~L}$ group, a significant increase was observed in the $\mathrm{R}$ value at the level of 1 and $1.5 \mathrm{~cm}$ below the lesser trochanter in comparison with the two proximal levels. Finally, in the $7 \mathrm{~L}$ group, no difference was found at the level of 0.5 and $1 \mathrm{~cm}$ below the lesser

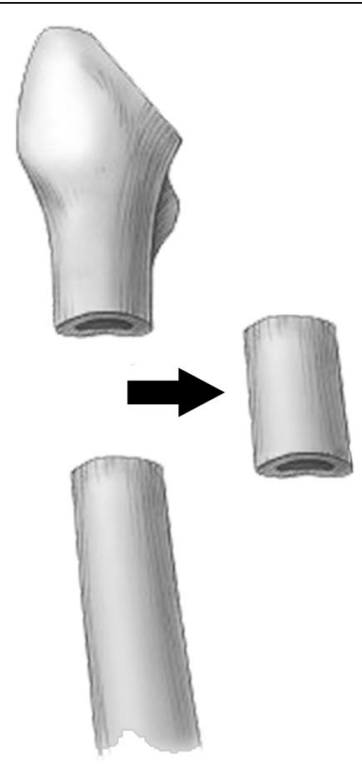

A
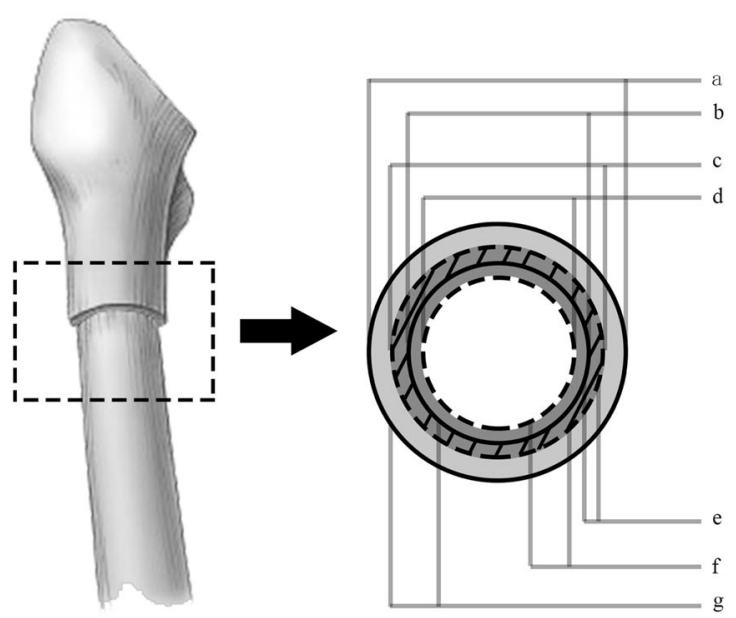

B
$\mathrm{C}$

Fig. 3 A-C (A) The segment is resected. (B) Coupling of the proximal and distal femurs. (C) Axis view of the interfaces: a: external diameter of the proximal segment $\left(M_{P}\right)$; b: inner diameter of the proximal segment $\left(N_{P}\right)$; $c$ : external diameter of the distal segment $\left(M_{D}\right)$; $d$ : inner diameter of the distal segment $\left(N_{D}\right)$; e: the overlapped area between the proximal and distal segments (contact area, S); f: area of the distal segment; and g: area of the proximal segment 
Table 1 The mean inner and external diameters at different levels of osteotomy

\begin{tabular}{lll}
\hline Level $(\mathrm{cm})$ & Inner Diameter $(\mathrm{mm})$ & External Diameter $(\mathrm{mm})$ \\
\hline 0 & 15.2 & 24.0 \\
0.5 & 13.8 & 23.3 \\
1 & 12.8 & 22.7 \\
1.5 & 12.1 & 22.3 \\
2 & 11.5 & 21.9 \\
2.5 & 11.1 & 21.5 \\
3 & 11.0 & 21.3 \\
3.5 & 10.8 & 21.1 \\
4 & 10.7 & 20.9 \\
4.5 & 10.7 & 20.9 \\
5 & 10.6 & 20.8 \\
5.5 & 10.4 & 20.8 \\
6 & 10.3 & 20.7 \\
6.5 & 10.2 & 20.7 \\
7 & 10.0 & 20.7 \\
7.5 & 9.9 & 20.7 \\
8 & 9.8 & 20.7 \\
\hline
\end{tabular}

trochanter, except for the position of just below the lesser trochanter, which had the smallest $R$ value. The results of the one-way ANOVA showed highly significant differences between the different levels in each group ( $p<0.0001$ for each group). These data are summarized in Table 3; the results of ANOVA and qtest of each group are showed in Additional files 1, 2, 3, $4,5,6,7,8,9,10,11,12,13$ and 14 .

\section{Discussion}

In Crowe type IV DDH, the anatomy of the hip joint is markedly distorted due to acetabular and femoral bone stock deficiency, narrower femoral canal, excessive anteversion of the femur, valgus neck-shaft angle, posterior location of the greater trochanter, soft tissue contractures, lower limb length discrepancy, and dysfunctional hip abduction [29, 30]. With these abnormalities, it is difficult to achieve and maintain a reduction in the true acetabulum. Therefore, sub-trochanteric femoral shortening osteotomy was devised to make reduction easier; however, it can be associated with complications, such as limping, sciatic nerve injury, and non-union of the osteotomy, or compromise the long-term survival of the stem.

Non-union of osteotomy may lead to varus angulation, pain, loss of rotational stability, and prosthetic loosening $[6,7,23]$. The incidence of non-union at the osteotomy site ranges from 0 to $22 \%[18,29,31-33]$. There are multiple contributing factors. The most important being the instability of the osteotomy site [34], which can be divided into three aspects. The first aspect is the type of the sub-trochanteric femoral shortening osteotomy; a transverse osteotomy was reported to have lower rotational stability than other techniques $[6,34]$, such as oblique, double-chevron, and Z-shaped. On the contrary,

Table 2 Contact Area at different levels and lengths of femoral osteotomy

\begin{tabular}{|c|c|c|c|c|c|c|c|c|c|c|c|c|c|c|}
\hline \multirow{2}{*}{$\begin{array}{l}\text { Level } \\
\text { (cm) }\end{array}$} & \multicolumn{14}{|c|}{ Length of Osteotomy $(\mathrm{cm})$} \\
\hline & 0.5 & 1 & 1.5 & 2 & 2.5 & 3 & 3.5 & 4 & 4.5 & 5 & 5.5 & 6 & 6.5 & 7 \\
\hline 0 & 315.40 & 286.26 & 266.63 & 248.11 & 231.41 & 222.98 & 215.45 & 206.18 & 203.00 & 200.89 & 199.94 & 197.79 & 197.16 & 194.03 \\
\hline 0.5 & 329.72 & 310.09 & 291.57 & 274.87 & 266.44 & 258.91 & 249.64 & 246.46 & 244.35 & 243.40 & 241.25 & 240.62 & 237.49 & 239.82 \\
\hline 1 & 339.95 & 321.43 & 304.73 & 296.30 & 288.77 & 279.51 & 276.32 & 274.21 & 273.26 & 271.11 & 270.48 & 267.35 & 269.68 & 267.95 \\
\hline 1.5 & 339.82 & 323.12 & 314.68 & 307.16 & 297.89 & 294.71 & 292.60 & 291.65 & 289.50 & 288.87 & 285.74 & 288.07 & 286.33 & NA \\
\hline 2 & 337.05 & 328.62 & 321.09 & 311.83 & 308.64 & 306.54 & 305.59 & 303.43 & 302.81 & 299.68 & 302.01 & 300.27 & NA & NA \\
\hline 2.5 & 337.96 & 330.43 & 321.16 & 317.98 & 315.87 & 314.92 & 312.77 & 312.14 & 309.01 & 311.34 & 309.61 & NA & NA & NA \\
\hline 3 & 334.22 & 324.96 & 321.77 & 319.66 & 318.71 & 316.56 & 315.93 & 312.80 & 315.13 & 313.40 & NA & NA & NA & NA \\
\hline 3.5 & 329.11 & 325.93 & 323.82 & 322.87 & 320.72 & 320.09 & 316.96 & 319.29 & 317.56 & NA & NA & NA & NA & NA \\
\hline 4 & 329.62 & 327.52 & 326.57 & 324.41 & 323.78 & 320.66 & 322.99 & 321.25 & NA & NA & NA & NA & NA & NA \\
\hline 4.5 & 327.73 & 326.77 & 324.62 & 323.99 & 320.87 & 323.20 & 321.46 & NA & NA & NA & NA & NA & NA & NA \\
\hline 5 & 329.59 & 327.44 & 326.81 & 323.68 & 326.01 & 324.28 & NA & NA & NA & NA & NA & NA & NA & NA \\
\hline 5.5 & 330.95 & 330.32 & 327.20 & 329.53 & 327.79 & NA & NA & NA & NA & NA & NA & NA & NA & NA \\
\hline 6 & 332.95 & 329.82 & 332.15 & 330.42 & NA & NA & NA & NA & NA & NA & NA & NA & NA & NA \\
\hline 6.5 & 331.94 & 334.27 & 332.54 & NA & NA & NA & NA & NA & NA & NA & NA & NA & NA & NA \\
\hline 7 & 338.91 & 337.17 & NA & NA & NA & NA & NA & NA & NA & NA & NA & NA & NA & NA \\
\hline 7.5 & 337.64 & NA & NA & NA & NA & NA & NA & NA & NA & NA & NA & NA & NA & NA \\
\hline 8 & NA & NA & NA & NA & NA & NA & NA & NA & NA & NA & NA & NA & NA & NA \\
\hline
\end{tabular}


Table 3 Coincidence Rate at different levels and lengths of femoral osteotomy

\begin{tabular}{|c|c|c|c|c|c|c|c|c|c|c|c|c|c|c|}
\hline \multirow{2}{*}{$\begin{array}{l}\text { Level } \\
\text { (cm) }\end{array}$} & \multicolumn{14}{|c|}{ Length of Osteotomy (cm) } \\
\hline & 0.5 & 1 & 1.5 & 2 & 2.5 & 3 & 3.5 & 4 & 4.5 & 5 & 5.5 & 6 & 6.5 & 7 \\
\hline 0 & $86.02 \%$ & $77.04 \%$ & $71.09 \%$ & $66.59 \%$ & $62.85 \%$ & $61.06 \%$ & $59.33 \%$ & $57.31 \%$ & $57.22 \%$ & $56.49 \%$ & $56.02 \%$ & $55.24 \%$ & $54.47 \%$ & $53.96 \%$ \\
\hline 0.5 & $90.79 \%$ & $84.98 \%$ & $80.05 \%$ & $76.61 \%$ & $74.88 \%$ & $73.47 \%$ & $71.42 \%$ & $71.27 \%$ & $70.25 \%$ & $69.24 \%$ & $68.32 \%$ & $67.54 \%$ & $66.73 \%$ & $66.94 \%$ \\
\hline 1 & $94.24 \%$ & $89.60 \%$ & $86.09 \%$ & $84.56 \%$ & $83.30 \%$ & $81.50 \%$ & $81.32 \%$ & $80.30 \%$ & $79.31 \%$ & $78.11 \%$ & $77.35 \%$ & $76.33 \%$ & $76.36 \%$ & $75.58 \%$ \\
\hline 1.5 & $95.18 \%$ & $91.74 \%$ & $90.23 \%$ & $89.06 \%$ & $87.52 \%$ & $87.40 \%$ & $86.44 \%$ & $85.30 \%$ & $84.24 \%$ & $83.51 \%$ & $82.40 \%$ & $82.38 \%$ & $81.54 \%$ & NA \\
\hline 2 & $96.53 \%$ & $95.01 \%$ & $93.87 \%$ & $92.44 \%$ & $92.21 \%$ & $91.40 \%$ & $90.24 \%$ & $89.20 \%$ & $88.40 \%$ & $87.30 \%$ & $87.16 \%$ & $86.27 \%$ & NA & NA \\
\hline 2.5 & $98.06 \%$ & $96.80 \%$ & $95.67 \%$ & $95.28 \%$ & $94.55 \%$ & $93.36 \%$ & $92.43 \%$ & $91.66 \%$ & $90.45 \%$ & $90.31 \%$ & $89.31 \%$ & NA & NA & NA \\
\hline 3 & $98.13 \%$ & $96.89 \%$ & $96.58 \%$ & $95.81 \%$ & $94.72 \%$ & $93.81 \%$ & $93.06 \%$ & $91.74 \%$ & $91.60 \%$ & $90.68 \%$ & NA & NA & NA & NA \\
\hline 3.5 & $98.23 \%$ & $97.84 \%$ & $96.93 \%$ & $95.88 \%$ & $94.96 \%$ & $94.09 \%$ & $92.90 \%$ & $92.69 \%$ & $91.80 \%$ & NA & NA & NA & NA & NA \\
\hline 4 & $98.90 \%$ & $98.06 \%$ & $97.09 \%$ & $96.16 \%$ & $95.06 \%$ & $94.03 \%$ & $93.85 \%$ & $92.99 \%$ & NA & NA & NA & NA & NA & NA \\
\hline 4.5 & $98.49 \%$ & $97.31 \%$ & $96.67 \%$ & $95.54 \%$ & $94.41 \%$ & $94.22 \%$ & $93.35 \%$ & NA & NA & NA & NA & NA & NA & NA \\
\hline 5 & $98.21 \%$ & $97.41 \%$ & $96.42 \%$ & $95.09 \%$ & $94.98 \%$ & $94.98 \%$ & 93.99\% & NA & NA & NA & NA & NA & NA & NA \\
\hline 5.5 & $98.69 \%$ & $97.86 \%$ & $96.52 \%$ & $96.20 \%$ & $95.21 \%$ & NA & NA & NA & NA & NA & NA & NA & NA & NA \\
\hline 6 & $98.49 \%$ & $97.35 \%$ & $97.01 \%$ & $96.20 \%$ & NA & NA & NA & NA & NA & NA & NA & NA & NA & NA \\
\hline 6.5 & $98.22 \%$ & $97.86 \%$ & $96.87 \%$ & NA & NA & NA & NA & NA & NA & NA & NA & NA & NA & NA \\
\hline 7 & $98.99 \%$ & $98.16 \%$ & NA & NA & NA & NA & NA & NA & NA & NA & NA & NA & NA & NA \\
\hline 7.5 & $98.36 \%$ & NA & NA & NA & NA & NA & NA & NA & NA & NA & NA & NA & NA & NA \\
\hline 8 & NA & NA & NA & NA & NA & NA & NA & NA & NA & NA & NA & NA & NA & NA \\
\hline
\end{tabular}

NA Not Available

Muratli et al. [34] performed a biomechanical study comparing four different sub-trochanteric osteotomy groups and demonstrated that there was no single inherent feature that increased the stability of the osteotomy designs. A comprehensive meta-analysis by Li et al. [14] reported no significant difference between the transverse and modified methods in terms of complications and survival rates. Transverse osteotomy, however, is a simple technique to adjust the anteversion angle with minimal damage to the periosteum at the osteotomy site $[14,15]$. Therefore, we chose this osteotomy technique as a viable mechanism for shortening the femur. The other two aspects that influence stability are the morphology of the femoral stem and the fixation method used. A cylindrical prosthesis, such as S-ROM stem (Courtesy of DePuy Orthopaedics, Warsaw, IN, USA), was recommended due to its distal slit and proximal fixation, which provides better distal engagement and facilitates rotational stability [25, 35, 36]. Several studies have also described transverse osteotomy with strut grafts using a cable or plate and screws for fixation [7, 32, 37]. Even cemented fixation of the stem has been used to improve the rotational stability $[19,22]$. Other factors, which affect union, are the contact area between the proximal and distal segments [18-20], bone stock, and vascularity. However, a limited bone contact area is a major disadvantage of transverse osteotomy, which may interfere with the bone healing process $[18,19]$. The consistency of the interfaces and canal diameters between the proximal and distal segments may contribute to union [20].
In order to promote union at the osteotomy site, we evaluated the contact area, $S$, and coincidence rate, $R$, between the proximal and distal fragments at different femoral osteotomy levels and lengths and then determined the optimal position of sub-trochanteric femoral shortening transverse osteotomy in patients with high developmental dysplasia.

Our results demonstrate that the dimensions of the femur, from 0 to $8 \mathrm{~cm}$ below the lesser trochanter, gradually decreased. However, the variations were less pronounced in comparison to the normal dimensions of the femur [38, 39]; the differences were 3.3 and $5.4 \mathrm{~mm}$ for the external and internal diameters, respectively. These results suggest that patients with Crowe type IV DDH have straighter intramedullary canals [30, 40]. Regarding the contact area and coincidence rate, different lengths of osteotomy presented different results. While the external and inner diameters of the cross-section of osteotomy did not change significantly in comparison to the normal dimensions of the femur, the coincidence rates were significantly higher at $2 \mathrm{~cm}$ below the lesser trochanter and below the level $(0.5-2.5 \mathrm{~L}$ groups $)$; at $1.5 \mathrm{~cm}$ below the lesser trochanter and below the level (3-5.5 L groups); at $1 \mathrm{~cm}$ below the lesser trochanter and below the level $(6-6.5 \mathrm{~L}$ groups); and at $0.5 \mathrm{~cm}$ below the lesser trochanter and below the level (7 L group). Furthermore, with increasing size of the resected femoral bone fragment, the contact area and coincidence rate gradually decreased. For example, at levels of $2 \mathrm{~cm}$ below the lesser 
trochanter, the contact area and coincidence rate were $308.6 \mathrm{~mm}^{2}$ and $92.2 \%$ in the $2.5 \mathrm{~L}$ group, respectively; $306.5 \mathrm{~mm}^{2}$ and $91.4 \%$ in the $3 \mathrm{~L}$ group, respectively; and $305.6 \mathrm{~mm}^{2}$ and $90.2 \%$ in the $3.5 \mathrm{~L}$ group, respectively. These results indicate that the proximal femur varied greatly, in both size and shape, relative to the distal femur, and the distal femur had straighter intramedullary canals in patients with Crowe type IV DDH. The findings that the contact area was not significantly different between the levels in the $0.5 \mathrm{~L}-2 \mathrm{~L}$ groups except for the level immediately below the lesser trochanter with the smallest contact area in the $2.5 \mathrm{~L}-7 \mathrm{~L}$ groups, may be explained by the following two reasons: the dimensions of the proximal femur varied greatly relative to those of the distal femur, and the diameter of the proximal femur was greater than that of the distal femur. Consequently, it was better to perform the osteotomy at the distal femur. However, two aspects should be considered. First, the level of $8 \mathrm{~cm}$ below the lesser trochanter always reached the femoral isthmus according to a study of Su et al. [28], which may influence the stability of prosthesis; therefore, osteotomy should not be performed at or below this level. Second, the femoral stem should bridge the osteotomy site by a certain distance. Ozan et al. suggested that the femoral stem should pass from the osteotomy site for at least 4-5 $\mathrm{cm}$ [41], while Yang et al. believed that the femoral stem bridged the osteotomy site by at least $3 \mathrm{~cm}$ [42]; even a depth of at least $7 \mathrm{~cm}$ below the osteotomy site has been previously reported [22]. For primary arthroplasty, the size of the femoral stem is usually slightly more than $10 \mathrm{~cm}$ from the distal part of the lesser trochanter to the distal end of the stem; therefore, the osteotomy site should not be too distal, in order to allow the stem to bridge with sufficient length. Therefore, it seems appropriate that the location of osteotomy should be shifted slightly distally in consideration of these factors. For example, in the $7 \mathrm{~L}$ group, there were just three levels of osteotomy. The contact area and coincidence rate were $194 \mathrm{~mm}^{2}$ and $54 \%$, respectively, at the level of just below the lesser trochanter, $239.8 \mathrm{~mm}^{2}$ and $66.9 \%$ at the level of $0.5 \mathrm{~cm}$ below the lesser trochanter, respectively, and $267.9 \mathrm{~mm}^{2}$ and $75.6 \%$ at the level of $1 \mathrm{~cm}$ below the lesser trochanter, respectively. Conclusively, it is better to choose the level of $1 \mathrm{~cm}$ below the lesser trochanter, although there were no significant differences between the levels at 1 and $0.5 \mathrm{~cm}$ below the lesser trochanter.

We recognize that there are several major limitations to our study. First, the number of patients was relatively small. However, the incidence of Crowe type IV DDH is relatively low, and it is difficult to obtain a larger data series from a single institution. Second, the method of assessing the radiographic diameter of the femoral canal was imprecise as the femoral canal is not precisely round; however, other studies [43-45] have used similar approximate methods to assess the diameter of the femoral canal, and, therefore, we believe our final assessments of the contact areas and coincidence rates are valid.

\section{Conclusions}

Subtrochanteric femoral shortening transverse osteotomy is a suitable technique relative to THA in patients with high DDH. The optimal location of osteotomy varied according to the size of the resected femoral bone fragment. Our findings may provide a reference for surgeons performing shortening transverse osteotomy. Further studies are needed to identify the most suitable location of osteotomy and improve the union at the osteotomy site.

\section{Supplementary information}

Supplementary information accompanies this paper at https://doi.org/10. 1186/s12891-020-03248-8.

Additional file 1: Table S1A that shows the result of one-way ANOVA of $0.5 \mathrm{~L}$ group. B that shows the result of q-test of $0.5 \mathrm{~L}$ group for contact area. $C$ that shows the q-test of q-test of $0.5 \mathrm{~L}$ group for coincidence rate.

Additional file 2: Table S2A that shows the result of one-way ANOVA of $1 \mathrm{~L}$ group. B that shows the result of q-test of $1 \mathrm{~L}$ group for contact area. $C$ that shows the q-test of $q$-test of $1 \mathrm{~L}$ group for coincidence rate.

Additional file 3: Table S3A that shows the result of one-way ANOVA of $1.5 \mathrm{~L}$ group. B that shows the result of q-test of $1.5 \mathrm{~L}$ group for contact area. $C$ that shows the q-test of q-test of $1.5 \mathrm{~L}$ group for coincidence rate.

Additional file 4: Table S4A that shows the result of one-way ANOVA of $2 \mathrm{~L}$ group. $B$ that shows the result of q-test of $2 \mathrm{~L}$ group for contact area. $C$ that shows the q-test of q-test of $2 \mathrm{~L}$ group for coincidence rate.

Additional file 5: Table S5A that shows the result of one-way ANOVA of $2.5 \mathrm{~L}$ group. $5 B$ that shows the result of q-test of $2.5 \mathrm{~L}$ group for contact area. $C$ that shows the q-test of q-test of $2.5 \mathrm{~L}$ group for coincidence rate.

Additional file 6: Table S6A that shows the result of one-way ANOVA of $3 \mathrm{~L}$ group. B that shows the result of q-test of $3 \mathrm{~L}$ group for contact area. $C$ that shows the $q$-test of q-test of $3 \mathrm{~L}$ group for coincidence rate.

Additional file 7: Table S7A that shows the result of one-way ANOVA of $3.5 \mathrm{~L}$ group. B that shows the result of q-test of $3.5 \mathrm{~L}$ group for contact area. $C$ that shows the q-test of q-test of $3.5 \mathrm{~L}$ group for coincidence rate.

Additional file 8: Table S8A that shows the result of one-way ANOVA of $4 \mathrm{~L}$ group. $B$ that shows the result of $q$-test of $4 \mathrm{~L}$ group for contact area. $C$ that shows the q-test of q-test of $4 \mathrm{~L}$ group for coincidence rate.

Additional file 9: Table S9A that shows the result of one-way ANOVA of $4.5 \mathrm{~L}$ group. B that shows the result of q-test of $4.5 \mathrm{~L}$ group for contact area. $C$ that shows the $q$-test of q-test of $4.5 \mathrm{~L}$ group for coincidence rate.

Additional file 10: Table S10A that shows the result of one-way ANOVA of $5 \mathrm{~L}$ group. B that shows the result of q-test of $5 \mathrm{~L}$ group for contact area. $C$ that shows the q-test of q-test of $5 L$ group for coincidence rate.

Additional file 11: Table S11A that shows the result of one-way ANOVA of $5.5 \mathrm{~L}$ group. B that shows the result of q-test of $5.5 \mathrm{~L}$ group for contact area. $C$ that shows the q-test of q-test of $5.5 \mathrm{~L}$ group for coincidence rate.

Additional file 12: Table S12A that shows the result of one-way ANOVA of $6 L$ group. $B$ that shows the result of $q$-test of $6 L$ group for contact area. $C$ that shows the q-test of q-test of $6 \mathrm{~L}$ group for coincidence rate.

Additional file 13: Table 13A that shows the result of one-way ANOVA of $6.5 \mathrm{~L}$ group. $B$ that shows the result of q-test of $6.5 \mathrm{~L}$ group for contact area. $C$ that shows the q-test of q-test of $6.5 \mathrm{~L}$ group for coincidence rate. 
Additional file 14: Table S14A that shows the result of one-way ANOVA of $7 L$ group. $B$ that shows the result of q-test of $7 L$ group for contact area. $C$ that shows the q-test of q-test of $7 \mathrm{~L}$ group for coincidence rate.

\section{Abbreviations}

DDH: Developmental dysplasia of the hip; THA: Total hip arthroplasty; PACS: Picture archiving and communication system; AP: Anteroposterior; ANOVA: Analysis of variance; q-test: Student-Newman-Keuls test

\section{Acknowledgements}

We thank Editage for assisting in the preparation of this manuscript.

\section{Authors' contributions}

Z-YH, HL and Z-MZ conceived and designed the study. Z-YH, HL and Z-MZ performed the study. Z-YH, Jl and J-HZ measured data. Z-YH, HL and ML analysed the data. $\mathrm{Z}-\mathrm{YH}$ and $\mathrm{HL}$ were involved in the writing of the manuscript. The authors read and approved the final manuscript.

\section{Funding}

Not applicable.

\section{Availability of data and materials}

The datasets used and/or analysed during the current study are available from the corresponding author on reasonable request.

\section{Ethics approval and consent to participate}

The research was performed according to the principles of the Declaration of Helsinki and was approved by our institutional ethics review board. The name of the ethics committee: Medical Technology Clinical Application Management Committee of Ningbo No.6 Hospital. The reference number: No 2019001

\section{Consent for publication}

Not applicable.

\section{Competing interests}

The authors declare that they have no competing interests.

Received: 11 July 2019 Accepted: 27 March 2020

\section{Published online: 06 April 2020}

\section{References}

1. Halawi M. Outcome measures in Total joint arthroplasty: current status, challenges, and future directions. Orthopedics. 2015:38:e685-9.

2. Watts CD, Abdel MP, Hanssen AD, Pagnano MW. Anatomic hip center decreases aseptic loosening rates after total hip arthroplasty with cement in patients with Crowe type-II dysplasia: a concise follow-up report at a mean of thirty-six years. J Bone Joint Surg Am. 2016;98:910.

3. Bicanic $G$, Delimar D, Delimar M, Pecina M. Influence of the acetabular cup position on hip load during arthroplasty in hip dysplasia. Int Orthop. 2009. 33:397-402.

4. Lai KA, Shen WJ, Huang LW, Chen MY. Cementless total hip arthroplasty and limb-length equalization in patients with unilateral Crowe type-IV hip dislocation. J Bone Joint Surg Am. 2005;87:339-45.

5. Krych AJ, Howard JL, Trousdale RT, Cabanela ME, Berry DJ. Total hip arthroplasty with shortening subtrochanteric osteotomy in Crowe type-IV developmental dysplasia: surgical technique. J Bone Joint Surg Am. 2010; 92(Suppl 1 Pt 2):176-87.

6. Kilicoglu OI, Turker M, Akgul T, Yazicioglu O. Cementless total hip arthroplasty with modified oblique femoral shortening osteotomy in Crowe type IV congenital hip dislocation. J Arthroplast. 2013;28:117-25.

7. Togrul E, Ozkan C, Kalaci A, Gulsen M. A new technique of subtrochanteric shortening in total hip replacement for Crowe type 3 to 4 dysplasia of the hip. J Arthroplast. 2010;25:465-70

8. Hua WB, Yang SH, Xu WH, Ye SN, Liu XZ, Wang J, et al. Total hip arthroplasty with subtrochanteric femoral shortening osteotomy for high hip dislocation. Orthop Surg. 2015;7:112-8.

9. Masonis JL, Patel JV, Miu A, Bourne RB, McCalden R, Macdonald SJ, et al. Subtrochanteric shortening and derotational osteotomy in primary total hip arthroplasty for patients with severe hip dysplasia: 5-year follow-up. J Arthroplast. 2003:18:68-73.

10. Koulouvaris P, Stafylas K, Sculco T, Xenakis T. Distal femoral shortening in total hip arthroplasty for complex primary hip reconstruction. A new surgical technique. J Arthroplast. 2008;23:992-8.

11. Paavilainen T. Total hip replacement for developmental dysplasia of the hip. Acta Orthop Scand. 1997;68:77-84.

12. Thorup B, Mechlenburg I, Soballe K. Total hip replacement in the congenitally dislocated hip using the Paavilainen technique: 19 hips followed for 1.5-10 years. Acta Orthop. 2009;80:259-62.

13. Hasegawa Y, Iwase T, Kanoh T, Seki T, Matsuoka A. Total hip arthroplasty for Crowe type developmental dysplasia. J Arthroplast. 2012;27:1629-35.

14. Li C, Zhang C, Zhang M, Ding Y. Comparison of transverse and modified subtrochanteric femoral shortening osteotomy in total hip arthroplasty for developmental dysplasia of hip: a meta-analysis. BMC Musculoskelet Disord. 2014;15:331

15. Ogawa H, Ito $Y$, Shinozaki M, Matsumoto K, Shimizu K. Subtrochanteric transverse shortening osteotomy in cementless total hip arthroplasty achieved using a modular stem. Orthopedics. 2011;34:170.

16. Mu W, Yang D, Xu B, Mamtimin A, Guo W, Cao L. Midterm outcome of Cementless Total hip arthroplasty in Crowe IV-Hartofilakidis type III developmental dysplasia of the hip. J Arthroplast. 2016;31:668-75.

17. Ollivier M, Abdel MP, Krych AJ, Trousdale RT, Berry DJ. Long-term results of Total hip arthroplasty with shortening subtrochanteric osteotomy in Crowe IV developmental dysplasia. J Arthroplast. 2016;31:1756-60.

18. Rollo G, Solarino G, Vicenti G, Picca G, Carrozzo M, Moretti B. Subtrochanteric femoral shortening osteotomy combined with cementless total hip replacement for Crowe type IV developmental dysplasia: a retrospective study. J Orthop Traumatol. 2017;18:407-13.

19. Oe K, lida H, Nakamura T, Okamoto N, Wada T. Subtrochanteric shortening osteotomy combined with cemented total hip arthroplasty for Crowe group IV hips. Arch Orthop Trauma Surg. 2013;133:1763-70.

20. Wang D, Li LL, Wang HY, Pei FX, Zhou ZK. Long-term results of Cementless Total hip arthroplasty with subtrochanteric shortening osteotomy in Crowe type IV developmental dysplasia. J Arthroplast. 2017;32:1211-9.

21. Howie CR, Ohly NE, Miller B. Cemented total hip arthroplasty with subtrochanteric osteotomy in dysplastic hips. Clin Orthop Relat Res. 2010;468:3240-7.

22. Kawai $\mathrm{T}$, Tanaka $\mathrm{C}$, Ikenaga M, Kanoe H. Cemented total hip arthroplasty with transverse subtrochanteric shortening osteotomy for Crowe group IV dislocated hip. J Arthroplast. 2011;26:229-35.

23. Ahmed E, Ibrahim el G, Ayman B. Total hip arthroplasty with subtrochanteric osteotomy in neglected dysplastic hip. Int Orthop. 2015;39:27-33.

24. Decking J, Decking R, Schoellner C, Fuerderer S, Rompe JD, Eckardt A. Cementless total hip replacement with subtrochanteric femoral shortening for severe developmental dysplasia of the hip. Arch Orthop Trauma Surg. 2003;123:357-62.

25. Zeng WN, Liu JL, Wang FY, Zhang X, Fan HQ, Chen GX, et al. Total hip arthroplasty for patients with Crowe type IV developmental dysplasia of the hip: ten years results. Int J Surg. 2017:42:17-21.

26. Zagra L, Bianchi L, Mondini A, Ceroni RG. Oblique femoral shortening osteotomy in total hip arthroplasty for high dislocation in patients with hip dysplasia. Int Orthop. 2015;39:1797-802.

27. Takao M, Ohzono K, Nishii T, Miki H, Nakamura N, Sugano N. Cementless modular total hip arthroplasty with subtrochanteric shortening osteotomy for hips with developmental dysplasia. J Bone Joint Surg Am. 2011;93:548-55.

28. Su XY, Zhao JX, Zhao Z, Zhang LC, Li C, Li JT, et al. Three-dimensional analysis of the characteristics of the Femoral Canal isthmus: an anatomical study. Biomed Res Int. 2015;2015:459612.

29. Park MS, Kim KH, Jeong WC. Transverse subtrochanteric shortening osteotomy in primary total hip arthroplasty for patients with severe hip developmental dysplasia. J Arthroplast. 2007;22:1031-6.

30. Sugano N, Noble PC, Kamaric E, Salama JK, Ochi T, Tullos HS. The morphology of the femur in developmental dysplasia of the hip. J Bone Joint Surg Br. 1998;80:711-9.

31. Biant LC, Bruce WJ, Assini JB, Walker PM, Walsh WR. Primary total hip arthroplasty in severe developmental dysplasia of the hip. Ten-year results using a cementless modular stem. J Arthroplast. 2009:24:27-32.

32. Bruce WJ, Rizkallah SM, Kwon YM, Goldberg JA, Walsh WR. A new technique of subtrochanteric shortening in total hip arthroplasty: surgical technique and results of 9 cases. J Arthroplast. 2000;15:617-26.

33. Wang D, Li DH, Li Q, Wang HY, Luo ZY, Yang Y, et al. Subtrochanteric shortening osteotomy during cementless total hip arthroplasty in young 
patients with severe developmental dysplasia of the hip. BMC Musculoskelet Disord. 2017;18:491.

34. Muratli KS, Karatosun V, Uzun B, Celik S. Subtrochanteric shortening in total hip arthroplasty: biomechanical comparison of four techniques. J Arthroplast. 2014;29:836-42.

35. Bao N, Meng J, Zhou L, Guo T, Zeng X, Zhao J. Lesser trochanteric osteotomy in total hip arthroplasty for treating CROWE type IV developmental dysplasia of hip. Int Orthop. 2013;37:385-90.

36. Necas L, Hrubina M, Melisik M, Cibula Z, Chmurny M, Daniel M, et al. Cementless hip arthroplasty and transverse shortening femoral osteotomy with the S-ROM stem for Crowe type IV developmental dysplasia. Eur J Orthop Surg Traumatol. 2019;29:1025-33.

37. Yasgur DJ, Stuchin SA, Adler EM, DiCesare PE. Subtrochanteric femoral shortening osteotomy in total hip arthroplasty for high-riding developmental dislocation of the hip. J Arthroplast. 1997:12:880-8.

38. Wei JK, Suzuki T. A macroscopic study of the cross section of femur. Okajimas Folia Anat Jpn. 1973;50:49-59.

39. Dokladal M. Significance of study of the cross section shape of the shaft of the femur for the identification of skeletal fragments. Folia Morphol (Warsz). 1972;20:270-2.

40. Noble PC, Kamaric E, Sugano N, Matsubara M, Harada Y, Ohzono K, Paravic $V$. Three-dimensional shape of the dysplastic femur: implications for THR Clin Orthop Relat Res. 2003;417:27-40.

41. Ozan F, Uzun E, Gurbuz K, Koyuncu S, Altay T, Kayali C. Total hip arthroplasty in the developmental dysplasia of the hip using transverse subtrochanteric osteotomy. J Orthop. 2016:13:259-63.

42. Yang TC, Chen CF, Tsai SW, Chen WM, Chang MC. Does restoration of hip center with subtrochanteric osteotomy provide preferable outcome for Crowe type III-IV irreducible development dysplasia of the hip?? J Chin Med Assoc. 2017;80:803-7.

43. Toni A, Fabbri F, Scimeca GB, Zanotti Russo MC, Baruffaldi F, Cianci R, et al, Computerized morphometric analysis of the femoral diaphyseal canal. Chir Organi Mov. 1995:80:207-19.

44. Uzel AP, Deloumeaux J, Rouvillain JL, Laflamme GY, Durandeau A, Caix P. Comparative study of femoral diaphyseal morphometry in two male populations, in France and a French West Indies island: an example of clinical relevance of comparative anatomy for orthopedic practice. Surg Radiol Anat. 2011;33:235-40.

45. Walsh KP, Fowler JR, Chen O, Gaughan JP, Ali S, Rehman M, et al. The validity and reliability of preoperative radiographic canal diameter measurements of the femur. HSS J. 2013;9:150-6.

\section{Publisher's Note}

Springer Nature remains neutral with regard to jurisdictional claims in published maps and institutional affiliations.

Ready to submit your research? Choose BMC and benefit from:

- fast, convenient online submission

- thorough peer review by experienced researchers in your field

- rapid publication on acceptance

- support for research data, including large and complex data types

- gold Open Access which fosters wider collaboration and increased citations

- maximum visibility for your research: over $100 \mathrm{M}$ website views per year

At $\mathrm{BMC}$, research is always in progress.

Learn more biomedcentral.com/submissions 